\title{
Occurrence of bacteria with a dangerous extent of antibiotic resistance in poultry in the Central Region of Moravia
}

\author{
Jan Bardon̆ ${ }^{1,2}$, Patrik Mlynárčik², Petra Procházková2, Magdaléna Röderová2, \\ Kristýna Mezerová ${ }^{2}$, Milan Koláŕ ${ }^{2}$ \\ ${ }^{1}$ State Veterinary Institute Olomouc, Czech Republic \\ ${ }^{2}$ Palacký University Olomouc, Faculty of Medicine and Dentistry, Department of Microbiology, \\ Olomouc, Czech Republic \\ Received February 7, 2018 \\ Accepted May 15, 2018
}

\begin{abstract}
The study aimed to determine the occurrence of Enterobacteriaceae producing broadspectrum beta-lactamases, vancomycin-resistant enterococci (VRE) and methicillin-resistant Staphylococcus aureus strains in poultry in Moravia, Czech Republic, including phenotypic and genotypic analyses of the extent of resistance. Using chromogenic screening media, a total of 240 clinical samples collected from poultry and the poultry farm environment were processed. Phenotypic tests identified 23 isolates of broad-spectrum beta-lactamase-producing Escherichia coli and one VRE isolate (Enterococcus faecium with VanA resistance). Methicillin-resistant Staphylococcus aureus strains were not detected. Among the isolates producing broad-spectrum beta-lactamases, 17 produced extended-spectrum beta-lactamases, most frequently CTX-M; the remaining 6 isolates were CIT-type AmpC enzymes. No carbapenemase-producing strains were detected. Pulsed-field gel electrophoresis showed that 21 E. coli strains $(91 \%)$ were genetically unrelated isolates. Increasing resistance of bacteria to antibiotic agents poses a serious issue for both human and veterinary medicine globally. For humans, a potential source of resistant bacteria may be animals or their products entering the human food chain, for example poultry. The presented study extends existing knowledge about the occurrence of resistant bacteria in poultry in Moravia and describes the phenotype and genotype of their resistance to antibiotics.
\end{abstract}

Escherichia coli, broad-spectrum beta-lactamases, vancomycin-resistant enterococci, methicillinresistant Staphylococcus aureus

Increasing resistance of bacteria to antibiotic agents poses a serious issue for both human and veterinary medicine, referred to as a global threat. Bacterial resistance to the effects of antibiotics stems from numerous causes combined with each other, making the phenomenon even more dangerous. The most important factors contributing to the development of bacterial resistance are the selection pressure of antibacterials, recombination processes leading to an exchange of the genetic material, and the horizontal spread of genetically identical strains of a particular species (Kolár et al. 2001; Kesselová et al. 2005; Urbánek et al. 2007; Htoutou Sedláková et al. 2014).

The above processes also occur in the animal setting; for humans, a potential source of resistant bacteria may be animals or their products entering the human food chain, for example poultry. The selection pressure of antibiotics may be manifested especially in animals routinely given water or feed containing antimicrobial agents. This category includes poultry. However, there are other routes of transmission of resistant bacteria between animals and humans. The examples are transmission via the food chain and direct or indirect contacts of people closely working with animals such as farmers or veterinarians. Important roles are also played by the environment and aquaculture contaminated with manure which are potential reservoirs of resistance genes (Economou and Gousia 
2015). The transmission of multiresistant strains from animals (animal foods) to humans is said to be mainly associated with Gram-negative bacteria producing broad-spectrum beta-lactamases, vancomycin-resistant enterococci (VRE) and methicillin-resistant Staphylococcus aureus (MRSA) strains.

The present study aimed to determine the prevalence of Enterobacteriaceae producing broad-spectrum beta-lactamases, VRE and MRSA in poultry in the Moravian part of the Czech Republic, including phenotypic and genotypic analyses of the extent of resistance of the isolates to antibiotics and determination of the genetic relationship of isolates.

\section{Materials and Methods}

Sample collection and processing

Between November 2015 and April 2017, a total of 240 samples obtained from the poultry farm environment and the caeca of broilers in Moravia were examined. Samples were collected on twelve farms (10 samples/ farm) and six poultry slaughterhouses (20 samples/slaughterhouse). In both cases, the samples were taken from domestic chickens (Gallus gallus). Environmental samples (120 samples) were obtained using sterile non-woven fabric covers put on decontaminated shoes and worn by a worker who walked on the bedding in a poultry shed. Subsequently, the shoe covers were put in a sterile bag and sent to a laboratory for analysis. Caecal contents (120 samples) were collected after slaughter at a processing plant and sent in sterile packaging to the laboratory.

In the laboratory, the shoe covers were put in peptone water (Trios, Czech Republic) which was incubated aerobically in a thermostat for $24 \mathrm{~h}$ at $37^{\circ} \mathrm{C}$. Then, the liquid medium was inoculated onto a selective chromogenic agar medium.

Caecal contents were inoculated with a loop directly onto a selective chromogenic agar medium. Both groups of samples were cultured using Oxoid chromogenic screening media, namely Brilliance MRSA Agar, Brilliance VRE Agar, Brilliance ESBL Agar and Brilliance CRE Agar (Thermo Fisher Scientific, UK). Inoculated agars were incubated aerobically for $24 \mathrm{~h}$ at $37^{\circ} \mathrm{C}$. For each batch, the quality of chromogenic media was verified with relevant reference strains.

\section{Species identification of isolates}

Suspected isolates with characteristic growth on different types of chromogenic media were isolated in pure culture onto blood agar (Trios, Czech Republic) to identify the species using MALDI - TOF MS (Biotyper Microflex, Bruker Daltonics, Germany).

\section{Phenotypic tests for determination of antibiotic resistance}

The identified isolates were subjected to phenotypic tests to determine their resistance to selected antibiotic agents using a standard microdilution method (EUCAST 2016). Enterobacteriaceae isolates were tested for resistance to gentamicin, sulphamethoxazole/trimethoprim, colistin, meropenem, ciprofloxacin, tigecycline, tobramycin and amikacin. An Enterococcus isolate was tested for resistance to ampicillin, ciprofloxacin, nitrofurantoin, vancomycin, teicoplanin, linezolid, and tigecycline. Reference strains Escherichia coli ATCC 25922, E. coli ATCC 35218, Pseudomonas aeruginosa ATCC 27853, S. aureus ATCC 29213 and Enterococcus faecalis ATCC 29212 were used for protocol quality control. For phenotypic detection of broad-spectrum beta-lactamases, a modified double-disk synergy test and AmpC test were used (Htoutou Sedlakova et al. 2011).

\section{Molecular biology tests for determination of antibiotic resistance}

More detailed determination of resistance mechanisms was performed with molecular biology tests detecting and analysing resistance genes. The polymerase chain reaction (PCR) mixture contained $1 \mu 1$ of deoxyribonucleic acid (DNA) - $100 \mathrm{ng}$ in $24 \mu \mathrm{l}$ of complete reaction buffer with $\mathrm{MgCl}_{2}$ (containing $100 \mathrm{mmol} / \mathrm{Tris}-\mathrm{HCl}[\mathrm{pH} 8.8]$, $500 \mathrm{mmol} / 1 \mathrm{KCl}, 1 \%$ Triton X-100, $15 \mathrm{mmol} / 1 \mathrm{MgCl}_{2}$ ) (Top-Bio, Czech Republic; $2.5 \mu \mathrm{l}$ ), deoxyribonucleotide triphosphate (dNTP) - $10 \mathrm{mmol} / \mathrm{l}, 0.2 \mu \mathrm{l}, 20 \mathrm{pmol}$ of each primer $(0.2 \mu \mathrm{l})$ and Taq DNA polymerase (Top-Bio; $0.2 \mu \mathrm{l})$. The PCR conditions were as follows: initial denaturation at $95^{\circ} \mathrm{C}$ for $7 \mathrm{~min}, 35$ cycles at $95^{\circ} \mathrm{C}$ for $40 \mathrm{~s}$, at different annealing temperatures for $40 \mathrm{~s}$ (Table 1 ) and $72{ }^{\circ} \mathrm{C}$ for $1 \mathrm{~min}$, followed by a single final elongation step at $72{ }^{\circ} \mathrm{C}$ for $7 \mathrm{~min}$. The primer sequences, concentrations, and calculated lengths of the corresponding amplicons are listed in Table 1.

\section{Detection of genetic relatedness of selected isolates}

To determine the genetic relatedness of $E$. coli isolates, macrorestriction analysis of chromosomal DNA was performed using pulsed-field gel electrophoresis (PFGE). Genomic DNAs prepared in accordance with a previously described procedure (Husickova et al. 2012) were digested with XbaI (30 U for $3 \mathrm{~h}$ ) (Takara, 
Bio, Otsu, Shiga, Japan) and subjected to PFGE as described elsewhere (Roderova et al. 2016). The resulting restriction profiles of isolates were compared using the GelCompareII software (Applied Maths, Kortrijk, Belgium). A dendrogram was created to determine clonal relatedness among the studied E. coli strains.

Table 1. Sequences of primers used for polymerase chain reaction for detection of resistance genes.

\begin{tabular}{|c|c|c|c|c|c|c|}
\hline Targeted gene & $\begin{array}{l}\text { Primer } \\
\text { name }\end{array}$ & Sequence $\left(5^{\prime} \text { to } 3^{\text {c }} \text { direction }\right)^{\mathrm{a}, \mathrm{b}}$ & $\begin{array}{l}\text { Length } \\
\text { (bases) }\end{array}$ & $\begin{array}{l}\text { Amplicon } \\
\text { size }\end{array}$ & $\begin{array}{l}\mathrm{Tm} \\
\left({ }^{0} \mathrm{C}\right)\end{array}$ & Reference \\
\hline & \multicolumn{6}{|c|}{ Escherichia coli } \\
\hline \multirow{2}{*}{$b l a_{\text {ТЕМ }}$ type } & TEM-F & 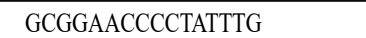 & 16 & \multirow{2}{*}{964 bp } & \multirow{2}{*}{56} & Olesen \\
\hline & TEM-R & ACCAATGCTTAATCAGTGAG & 20 & & & et al. 2004 \\
\hline \multirow{2}{*}{$b l a_{\mathrm{SHV}}$ type } & SHV-F & CTTTACTCGCCTTTATCG & 18 & \multirow{2}{*}{$827 \mathrm{bp}$} & \multirow{2}{*}{56} & Chanawong \\
\hline & SHV-R & TCCCGCAGATAAATCACCA & 19 & & & et al. 2000 \\
\hline \multirow{2}{*}{$b l a_{\text {СТХ-м }}$ type } & CTX-M-F & ATGTGCAGYACCAGTAARGT & 20 & \multirow{2}{*}{593 bp } & \multirow{2}{*}{56} & \multirow{2}{*}{$\begin{array}{r}\text { Pagani } \\
\text { et al. } 2003\end{array}$} \\
\hline & CTX-M-R & TGGGTRAARTARGTSACCAGA & 21 & & & \\
\hline \multirow{6}{*}{ bla ${ }_{\mathrm{OXA}}$ type } & OXA-1F & ACACAATACATATCAACTTCGC & 22 & \multirow{2}{*}{$813 \mathrm{bp}$} & \multirow{2}{*}{56} & Steward \\
\hline & OXA-1R & AGTGTGTTTAGAATGGTGATC & 21 & & & et al. 2001 \\
\hline & OXA-2F & TTCAAGCCAAAGGCACGATAG & 21 & \multirow{2}{*}{702 bp } & \multirow{2}{*}{58} & Steward \\
\hline & OXA-2R & TCCGAGTTGACTGCCGGGTTG & 21 & & & et al. 2001 \\
\hline & OXA-10F & CGTGCTTTGTAAAAGTAGCAG & 21 & \multirow{2}{*}{$651 \mathrm{bp}$} & \multirow{2}{*}{56} & Steward \\
\hline & OXA-10R & CATGATTTTGGTGGGAATGG & 20 & & & et al. 2001 \\
\hline \multirow{2}{*}{$\begin{array}{l}b l a_{\text {AmpC-CIT }} \\
\left(b^{2} a_{\mathrm{LAT}} \text { type, }\right. \\
\text { bla }_{\mathrm{CMY}} \text { type, } \\
\left.\text { bla }_{\mathrm{BII}} \text { type }\right)\end{array}$} & CIT-F & TGGCCAGAACTGACAGGCAAA & 21 & \multirow[b]{2}{*}{462 bp } & \multirow[b]{2}{*}{64} & Perez-Perez \\
\hline & CIT-R & TTTCTCCTGAACGTGGCTGGC & 21 & & & $\begin{array}{r}\text { and Hanson } \\
2002\end{array}$ \\
\hline \multirow{3}{*}{$\begin{array}{l}\text { bla }_{\text {Ampc-Mox }} \\
\left(\text { bla }_{\mathrm{MOx}} \text { type, }\right. \\
\text { bla }_{\text {СмҮ }} \text { type) }\end{array}$} & MOX-F & GCTGCTCAAGGAGCACAGGAT & 21 & \multirow{3}{*}{$520 \mathrm{bp}$} & \multirow{3}{*}{64} & Perez-Perez \\
\hline & & & & & & and Hanson \\
\hline & MOX-R & CACATTGACATAGGTGTGC & 19 & & & 2002 \\
\hline \multirow{2}{*}{ bla $_{\mathrm{DHA}}$ type } & DHA-F & AACTTTCACAGGTGTGCTGGGT & 22 & \multirow{2}{*}{405 bp } & \multirow{2}{*}{64} & Perez-Perez and \\
\hline & DHA-R & CCGTACGCATACTGGCTTTGC & 21 & & & Hanson 2002 \\
\hline \multirow{2}{*}{$b l a_{\mathrm{ACC}}$ type } & ACC-F & AACAGCCTCAGCAGCCGGTTA & 21 & $346 \mathrm{hn}$ & 64 & Perez-Perez and \\
\hline & ACC-R & TTCGCCGCAATCATCCCTAGC & 21 & & & Hanson 2002 \\
\hline$b l a_{\text {AmpC-EBC }}$ & EBC-F & TCGGTAAAGCCGATGTTGCGG & 21 & & & Perez-Perez and \\
\hline (bla ${ }_{\mathrm{MIR}}$ type, & & 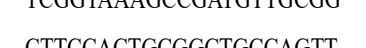 & 21 & 302 bp & 64 & Hanson \\
\hline bla $a_{\mathrm{ACT}}$ type) & EBC-R & CTTCCACTGCGGCTGCCAGTT & 21 & & & 2002 \\
\hline ype & FOX-F & AACATGGGGTATCAGGGAGAT & 21 & $190 \mathrm{bp}$ & 64 & Perez-Perez and \\
\hline & FOX-R & CAAAGCGCGTAACCGGATTGG & 21 & & & Hanson 2002 \\
\hline & & & occus & & & \\
\hline & VanA-F & GGGAAAACGACAATTGC & 17 & $732 \mathrm{~b}$ & 62 & Dutkamalen \\
\hline & VanA-R & GTACAATGCGGCCGTTA & 17 & & & et al. 1995 \\
\hline nA/B lype & VanB-F & ATGGGAAGCCGATAGTC & 17 & $635 \mathrm{bp}$ & 62 & Dutkamalen \\
\hline & VanB-R & GATTTCGTTCCTCGACC & 17 & & & et al. 1995 \\
\hline & & & coccu. & & & \\
\hline & MecA-F & TCCAGATTACAACTTCACCAGG & 22 & & 53 & Oliveira and \\
\hline & MecA-R & CCACTTCATATCTTGTAACG & 20 & 162 bp & 53 & de Lencastre 2002 \\
\hline
\end{tabular}

${ }^{\mathrm{a}}$ For degenerate primers: $\mathrm{R}=\mathrm{A}$ or $\mathrm{G} ; \mathrm{S}=\mathrm{G}$ or $\mathrm{C} ; \mathrm{Y}=\mathrm{C}$ or $\mathrm{T}$. ${ }^{\mathrm{b}}$ Concentration of each of the primers was 20 pmol. 


\section{Results}

A total of 240 samples were processed using various screening media. Among those, phenotypic tests identified 23 isolates (9.6\%) producing broad-spectrum beta-lactamases. Additionally, one case of VRE was identified. No MRSA strains were found.

All isolates producing broad-spectrum beta-lactamases were E. coli. In 17 isolates, the exended spectrum beta-lactamases (ESBL) phenotype was detected. The CTX-M-type ESBL production was confirmed in 14 strains, with two and four strains being also of the SHV and TEM types, respectively. Additionally, two strains produced both TEM and SHV ESBLs and one strain produced only SHV-type ESBL. The remaining 6 isolates were the CIT-type AmpC enzymes, with the CIT complex comprising, for example, CMY-2/-3/-4, LAT-1/-2, and BIL1. No carbapenemase-producing strains were found. As seen from Table 2 , tests assessing the resistance of $E$. coli isolates to selected antibiotics showed higher resistance to ciprofloxacin and sulphamethoxazole/trimethoprim. No other significant resistance phenotypes were noted. Detailed specifications and prevalence rates for resistance genotypes of $E$. coli strains producing broad-spectrum beta-lactamases are shown in Table 3.

Table 2. Results of resistance tests for Escherichia coli $(\mathrm{n}=23)$.

\begin{tabular}{lcccccccc}
\hline Tested antibiotic & GEN & COT & COL & MER & CIP & TIG & TOB & AMI \\
Susceptible strains (n) & 23 & 16 & 23 & 23 & 9 & 23 & 23 & 23 \\
Resistant strains (n) & 0 & 7 & 0 & 0 & 14 & 0 & 0 & 0 \\
Resistance (\%) & 0 & 30.4 & 0 & 0 & 60.9 & 0 & 0 & 0 \\
\hline
\end{tabular}

Legend: $\mathrm{n}$ - number of tested isolates, GEN - gentamicin, COT - sulphamethoxazole + trimethoprim, COL - colistin, MER - meropenem, CIP - ciprofloxacin, TIG - tigecycline, TOB - tobramycin, AMI - amikacin

Table 3. Prevalence of resistant strains of Escherichia $\operatorname{coli}(\mathrm{n}=23)$ by type of resistance.

\begin{tabular}{llr}
\hline Identified genotype & $\mathrm{n}$ & $\%$ \\
\hline ESBL $\left(\right.$ bla $\left._{\mathrm{CTX}-\mathrm{M}}\right)$ & 8 & 34.8 \\
ESBL $\left(\right.$ bla $\left._{\mathrm{SHV}}, b l a_{\mathrm{CTX}-\mathrm{M}}\right)$ & 2 & 8.3 \\
ESBL $\left(\right.$ bla $\left._{\mathrm{TEM}}, b l a_{\mathrm{SHV}}\right)$ & 2 & 8.3 \\
ESBL $\left(\right.$ bla $\left._{\mathrm{TEM}}, b l a_{\mathrm{CTX}-\mathrm{M}}\right)$ & 4 & 16.7 \\
ESBL $\left(\right.$ bla $\left.a_{\mathrm{SHV}}\right)$ & 1 & 4.2 \\
AmpC $($ CIT-type $)$ & 6 & 25.0 \\
\hline
\end{tabular}

ESBL - extended-spectrum beta-lactamases; $\mathrm{n}$ number of tested isolates
Pulsed-field gel electrophoresis was used to determine the clonality of all 23 tested E. coli isolates producing broad-spectrum beta-lactamases (ESBL and AmpC). Twentyone strains were confirmed to be genetically unrelated isolates. The remaining two CTX-M-type ESBL producers (strains S5113 and S5115) were found to be identical strains based on comparison of their restriction profiles (Fig. 1). Subsequently, the two strains were found to come from different sheds located at the same farm.

Among the 240 tested samples, only one case of VRE was identified. This was an Enterococcus faecium isolate with the VanA type of resistance. This strain was only susceptible to linezolid and tigecycline, and resistant to the other tested antibiotics (i.e. ampicillin, ciprofloxacin, nitrofurantoin, vancomycin and teicoplanin).

\section{Discussion}

The occurrence of multiresistant strains in the food chain may lead to colonization of the human intestinal tract, allowing subsequent interhuman transmission. The sources may be animal meat, milk and eggs. In case of primary contamination, the animal itself is the carrier of a multiresistant strain. However, secondary contamination of the food chain 


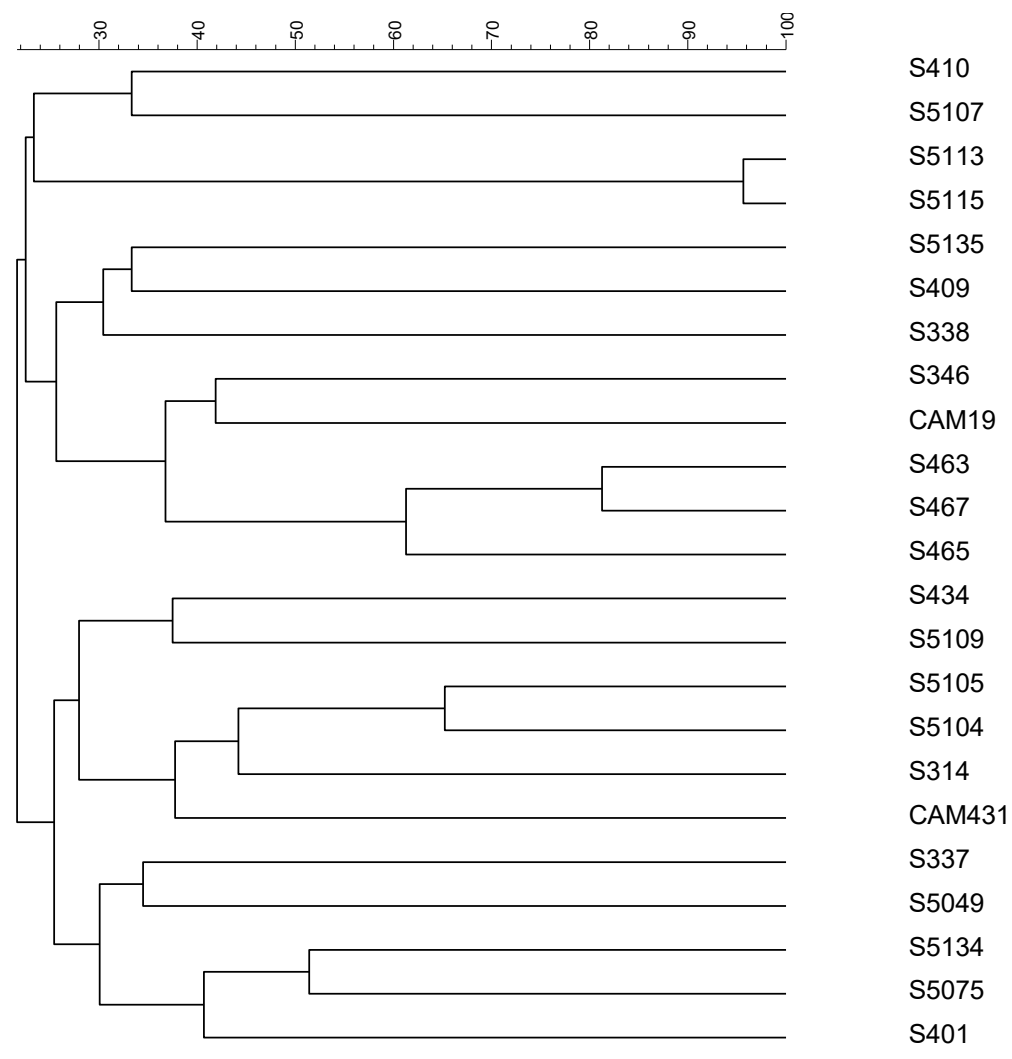

Fig. 1. Dendrogram of broad-spectrum beta-lactamase-producing Escherichia coli

may occur if raw materials or foods of animal origin are processed, transported or stored. Special attention should be paid to foods of animal origin which have not been heat-treated. Bacteria with a dangerous degree of resistance to antibiotics that threaten the treatment of human infections are mainly bacteria producing broad-spectrum beta-lactamases (e.g. ESBL, AmpC and carbapenemases in case of Enterobacteriaceae), MRSA, VRE and bacteria with resistance to fluoroquinolones (e.g. E. coli). Potential carriers of this resistance are bacteria commonly occurring in foods for which no large-scale monitoring has been performed as yet (EFSA 2016). An increased incidence of broad-spectrum beta-lactamaseproducing $E$. coli has been observed in food-producing animals such as cattle, chickens and pigs. These findings suggest that animals and foods may be sources of resistant bacteria for humans as well (WHO 2011; Reich et al. 2013).

In the present study, broad-spectrum beta-lactamase-producing $E$. coli was isolated in only $9.6 \%$ of 240 tested samples (cloacal swabs, environment). For example, Egea et al. (2012) reported a contamination of raw poultry meat with ESBL-producing E. coli of $93.3 \%$. Overdevest et al. (2011) found a high prevalence of bacteria carrying genes encoding ESBL in retail chicken meat samples (79.8\% of positive samples), with genetic analysis showing that ESBL-positive strains identical with those from human rectal swabs prevailed. The higher prevalence rates of bacteria in poultry meat compared to clinical samples (cloacal swabs) may be due to secondary contamination of meat during slaughter and subsequent manipulation. A similar situation has been observed, for example, in 
Campylobacter spp., with the prevalence of these bacteria being lower in the caeca than on the animals' injured skin or in fresh poultry meat in retail (Bardoň et al. 2011).

Escherichia coli isolates mainly harbour different ESBL genes (bla ${ }_{\text {CTX, }} b l a_{\text {TEM }}$ and $b l a_{\mathrm{SHV}}$ ) and AmpC genes (bla $a_{\mathrm{ACC}}$ and $b l a_{\mathrm{CMY}}$ ) (Dierikx et al. 2010; Kolar et al. 2010). Furthermore, Randall et al. (2011) showed that many of the chicken or turkey isolates tested were positive for the bla $a_{\text {OXA }}$ genes (Randall et al. 2011). Moreover, several MCR-1-producing $E$. coli isolates have been detected from chicken meat coproducing either an ESBL (SHV-12) or an AmpC (CMY-2) cephalosporinase, or both (Hasman et al. 2015). In addition, bla $a_{\mathrm{DHA}}$ and bla ${ }_{\mathrm{ACT} \text {-like }}$ AmpC beta-lactamases have been reported in Salmonella enterica isolated from chicken farms in South Korea and Klebsiella pneumoniae in chickens in China, respectively (Rayamajhi et al. 2010; Wu et al. 2012). The presence of ESBL/AmpC genes in E. coli from food-producing animals may present a risk to human health. Interestingly, Laube et al. (2013) reported that faeces, litter, and even dust may act as transmission sources of ESBL/AmpC-producing E. coli in a broiler barn. Besides, isolation of ESBL-producing $E$. coli from flies has been described, suggesting a potential alternative route of transmission of ESBL-producing E. coli from poultry to humans (Blaak et al. 2014). Another factor that could influence the high detection rates of beta-lactamases in the investigated farms is the intensive use of antibiotics. In the present study, the most common genotype identified in $E$. coli isolates was the ESBL bla ${ }_{\text {CTX-M }}$ (34.8\%), followed by CIT-type AmpC (25\%). No strains producing carbapenemases and resistant to colistin were detected.

Analysis of 23 broad-spectrum beta-lactamase-producing E. coli isolates failed to show marked clonal spread of this type of resistance on poultry farms. Twenty-one strains were confirmed to be genetically unrelated isolates. Only two CTX-M-type ESBL producers were found to be identical strains. This is consistent with a study by Casella et al. (2017) showing that positive ESBL-producing E. coli isolates mostly did not spread clonally.

In the present study, the prevalence of VRE was very low. Among 240 tested samples, only one case of VRE was identified, namely E. faecium, subsequently found to have the VanA type of resistance. Our previous research on VRE in poultry in the Olomouc Region, Moravia, showed a higher prevalence of VRE in poultry. In 2002-2004, for example, a total of 527 strains of Enterococcus spp. were isolated from 1,050 cloacal swabs collected from poultry in the region. Vancomycin-resistant enterococci were detected in 11 cases $(2.1 \%)$. Most isolates $(54.5 \%)$ were identified as E. faecium with the VanA type of resistance (Kolár et al. 2005). Compared to the 2002-2004 findings, the prevalence of VRE on poultry farms in the present study is not alarming; however, the monitoring of resistance needs to be continued.

The increasing resistance of bacteria to the effects of antibiotic therapy is a major problem in both veterinary and human medicine. Its solution requires understanding the development and spread of resistance between humans and animals. The essential prerequisite is close interdisciplinary cooperation and surveillance of bacterial resistance; its integral part is the determination of the type of selection, ways and mechanisms of spread of multiresistant bacteria, including the genetic basis.

The presented study extends existing knowledge about the occurrence of resistant bacteria in poultry in Moravia and describes the phenotype and genotype of their resistance to antibiotics. More detailed determination of resistance mechanisms was performed with molecular biology tests especially in the case of broad-spectrum beta-lactamase-producing E. coli isolates. 


\section{References}

Bardoň J, Kolář M, Karpíšková R, Hricová K 2011: Prevalence of thermotolerant Campylobacter spp. in broilers at retail in the Czech Republic and their antibiotic resistance. Food Control. 22: 328-332

Blaak H, Hamidjaja RA, van Hoek AH, de Heer L, de Roda Husman AM, Schets FM 2014: Detection of extendedspectrum beta-lactamase (ESBL)-producing Escherichia coli on flies at poultry farms. Appl Environ Microb 80: $239-246$

Casella T, Correa M, Nogueira L, Saras E, Haenni M, Madec JY 2017: High prevalence of ESBLs in retail chicken meat despite reduced use of antimicrobials in chicken production, France. Int J Food Microbiol 257: 271-275

Dierikx C, van Essen-Zandbergen A, Veldman K, Smith H, Mevius D 2010: Increased detection of extended spectrum beta-lactamase producing Salmonella enterica and Escherichia coli isolates from poultry. Vet Microbiol 145: 273-278

Dutkamalen S, Evers S, Courvalin P 1995: Detection of glycopeptide resistance genotypes and identification to the species level of clinically relevant enterococci by PCR. J Clin Microbiol 33: 1434-1434

Economou V, Gousia P 2015: Agriculture and food animals as a source of antimicrobial-resistant bacteria. Infect Drug Resist 8: 49-61

EFSA (European Food Safety Authority) and ECDC (European Centre for Disease Prevention and Control), 2016: The European Union summary report on antimicrobial resistance in zoonotic and indicator bacteria from humans, animals and food in 2014. EFSA Journal 14: 3-14

Egea P, Lopez-Cerero L, Torres E, Gomez-Sanchez M del C, Serrano L, Navarro Sanchez-Ortiz MD, RodriguezBano J, Pascual A 2012: Increased raw poultry meat colonization by extended spectrum beta-lactamaseproducing Escherichia coli in the south of Spain. Int J Food Microbiol 159: 69-73

EUCAST - European Committee on Antimicrobial Susceptibility Testing 2016: Breakpoint Tables for Interpretation of MICs and Zone diameters [online]. Available from <http://www.eucast.org/clinical_breakpoints> [accessed on 9 March 2016]

Hasman H, Hammerum AM, Hansen F, Hendriksen RS, Olesen B, Agerso Y, Zankari E, Leekitcharoenphon P, Stegger M, Kaas RS, Cavaco LM, Hansen DS, Aarestrup FM, Skov RL 2015: Detection of mcr-1 encoding plasmid-mediated colistin-resistant Escherichia coli isolates from human bloodstream infection and imported chicken meat, Denmark 2015. Euro Surveill 20: 1-5

Husickova V, Cekanova L, Chroma M, Htoutou-Sedlakova M, Hricova K, Kolar M 2012: Carriage of ESBL- and AmpC-positive Enterobacteriaceae in the gastrointestinal tract of community subjects and hospitalized patients in the Czech Republic. Biomed Pap Med Fac Univ Palacky Olomouc Czech Repub 156: $348-353$

Htoutou Sedlakova M, Hanulik V, Chroma M, Hricova K, Kolar M, Latal T, Schaumann R, Rodloff AC 2011: Phenotypic detection of broad-spectrum beta-lactamases in microbiological practice Med Sci Monit 17: 147-152

Htoutou Sedláková M, Urbánek K, Vojtová V, Suchánková H, Imwensi P, Kolář M 2014: Antibiotic consumption and its influence on the resistance in Enterobacteriaceae. BMC Res Notes 7: 1-10

Chanawong A, M'Zali FH, Heritage J, Lulitanond A, Hawkey PM 2000: Characterisation of extended-spectrum beta-lactamases of the SHV family using a combination of PCR-single strand conformational polymorphism (PCR-SSCP) and PCR-restriction fragment length polymorphism (PCR-RFLP). FEMS Microbiol Lett 184: 85-89

Kesselová M, Kolář M, Sauer P, Koukalová D, Petrželová J, Vágnerová I, Kohnová I, Kantor L, Urbánek K 2005: Molekulárně-biologická analýza ESBL- pozitivních kmenů Klebsiella pneumoniae na novorozeneckém oddělení Fakultní nemocnice Olomouc. Klin Mikrobiol Inf Lék 11: 20-24

Kolar M, Bardon J, Chroma M, Hricova K, Stosova T, Sauer P, Koukalova D 2010: ESBL and AmpC beta-lactamase-producing Enterobacteriaceae in poultry in the Czech Republic. Vet Med (Praha) 55: 119-124

Kolář M, Bardon̆ J 2011: Klinický význam bakteriální rezistence k antimikrobním látkám. Vet Med (Praha) 8: 14-17

Kolar M, Pantucek R, Bardon J, Cekanova L, Kesselova M, Sauer P, Vagnerova I, Koukalova D 2005: Occurrence of vancomycin-resistant enterococci in humans and animals in the Czech Republic between 2002 and 2004. J Med Microbiol 54: 1-3

Kolář M, Urbánek K, Látal T 2001: Antibiotic selection pressure and development of bacterial resistance. Intern J Antimicrob Agents 17: 357-363

Laube H, Friese A, von Salviati C, Guerra B, Kasbohrer A, Kreienbrock L, Roesler U 2013: Longitudinal monitoring of extended-spectrum-beta-lactamase/AmpC-producing Escherichia coli at German broiler chicken fattening farms. Appl Environ Microbiol 79: 4815-4820

Olesen I, Hasman H, Aarestrup FM 2004: Prevalence of beta-lactamases among ampicillin-resistant Escherichia coli and Salmonella isolated from food animals in Denmark. Microb Drug Resist 10: 334-340 
Oliveira DC, de Lencastre H 2002: Multiplex PCR strategy for rapid identification of structural types and variants of the mec element in methicillin-resistant Staphylococcus aureus. Antimicrob Agents Chemother 46: 2155-2161

Overdevest I, Willemsen I, Rijnsburger M, Eustace A, Xu L, Hawkey P, Heck M, Savelkoul P, VandenbrouckeGrauls C, van der Zwaluw K, Huijsdens X, Kluytmans J 2011: Extended-spectrum $\beta$-lactamase genes of Escherichia coli in chicken meat and humans, the Netherlands. Emerg Infect Dis 17: 1216-1222

Pagani L, Dell'Amico E, Migliavacca R, D'Andrea MM, Giacobone E, Amicosante G, Romero E, Rossolini G 2003: Multiple CTX-M-type extended-spectrum $\beta$-lactamases in nosocomial isolates of Enterobacteriaceae from a hospital in northern Italy. J Clin Microbiol 41: 4264-4269

Perez-Perez FJ, Hanson ND 2002: Detection of plasmid-mediated AmpC beta-lactamase genes in clinical isolates by using multiplex PCR. J Clin Microbiol 40: 2153-2162

Randall LP, Clouting C, Horton RA, Coldham NG, Wu G, Clifton-Hadley FA, Davies RH, Teale CJ 2011: Prevalence of Escherichia coli carrying extended-spectrum beta-lactamases (CTX-M and TEM-52) from broiler chickens and turkeys in Great Britain between 2006 and 2009. J Antimicrob Chemother 66: 86-95

Rayamajhi N, Jung B, Cha SB, Shin MK, Kim A, Kang MS, Lee KM, Yoo HS 2010: Antibiotic resistance patterns and detection of blaDHA-1 in Salmonella species isolates from chicken farms in South Korea. Appl Environ Microbiol 76: 4760-4764

Reich F, Atanassova V, Klein G 2013: Extended-spectrum $\beta$-lactamase- and AmpC-producing enterobacteria in healthy broiler chickens, Germany. Emerg Infect Dis 19: 1253-1259

Roderova M, Halova D, Papousek I, Dolejska M, Masarikova M, Hanulik V, Pudova V, Broz P, Htoutou-Sedlakova M, Sauer P, Bardon J, Cizek A, Kolar M, Literak I 2016: Characteristics of quinolone resistance in Escherichia coli isolates from humans, animals, and the environment in the Czech Republic. Front Microbiol 7: 1-12

Steward CD, Rasheed JK, Hubert SK, Biddle JW, Raney PM, Anderson GJ, Williams PP, Brittain KL, Oliver A, McGowan JE Jr, Tenover FC 2001: Characterization of clinical isolates of Klebsiella pneumoniae from 19 laboratories using the National Committee for Clinical Laboratory Standards extended-spectrum betalactamase detection methods. J Clin Microbiol 39: 2864-2872

Urbánek K, Kolář M, Lovečková Y, Strojil J, Šantavá L 2007: Influence of 3rd generation cephalosporin utilization on the occurrence of ESBL-positive Klebsiella pneumoniae strains. J Clin Pharm Ther 32: 403-408

World Health Organization 2011: Tackling Antibiotic Resistance from a Food Safety Perspective in Europe. Copenhagen: World Health Organization; 2011. [Accessed December 15, 2014]. Available from: http://www.euro.who.int/_data/assets/pdf_file/0005/136454/e94889.pdf.

Wu H, Liu BG, Liu JH, Pan YS, Yuan L, Hu GZ 2012: Phenotypic and molecular characterization of CTX-M-14 extended-spectrum beta-lactamase and plasmid-mediated ACT-like AmpC beta-lactamase produced by Klebsiella pneumoniae isolates from chickens in Henan Province, China. Genet Mol Res 11: 3357-3364 